\title{
Comparison of Cost Effectiveness of Complementary \& Alternative Medicine and Conventional Medicine in the Treatment of Rheumatoid Arthritis in Two Public Hospitals of Bangladesh
}

\author{
Jakir Hossain Bhuiyan Masud ${ }^{1}$, Anu Aggarwal ${ }^{2}$
}

\begin{abstract}
Background: Rheumatoid arthritis (RA) is one of the main causes of disability worldwide. Currently, controversy remains about the best therapeutic alternatives such as complementary and alternative medicine (CAM) and conventional medicine (CM) for this disease when evaluated from a cost effectiveness viewpoint. Objective: To examine the cost effectiveness of CAM and CM in the treatment of RA. Materials and method: The data were collected from Dhaka Medical College Hospital and Government Unani and Ayurvedic Medical College Hospital from August 2008 to February 2009 by primary sources in the study. Total 60 patients were included who had been treated for six months. Patients were assessed with EuroQol 5D (EQ-5D) tool. Results: The outcome is more effective in CAM than CM by EuroQol 5D. The EQ-5D average outcome of CAM is 0.239 and CM is 0.202. The cost of CAM is also lower than that of $C M$. Conclusion: Our results support that complementary and alternative medicine (CAM) is a more cost-effective option, compared to the conventional medicine for the treatment of $R A$.
\end{abstract}

Key words: Rheumatoid arthritis; complementary medicine; alternative medicine; conventional medicine; EuroQol 5D.

Delta Med Col J. Jul 2019;7(2):76-79

\section{Introduction}

Rheumatoid arthritis (RA) is an autoimmune disease that causes joint pain and leads to disability. The CDC reported an estimated $22.7 \%$ (54.4 million) of adults had doctor-diagnosed arthritis and prevalence is more in women $(23.5 \%)$ than in men (18.1\%) aged $\geq 18$ years from the National Health Interview Survey (NHIS) years 2013-2015.1 The World Health Organization (WHO) and International League of Associations of Rheumatology (ILAR) initiated the COPCORD project in 1981 to control rheumatic diseases by both prevention and treatment. ${ }^{2}$ In developed countries, the prevalence of RA is around $0.5 \%$ to
$1.0 \%$ among adult population, and the prevalence is higher in women than in men. ${ }^{3,4}$ Different factors are associated with the prevalence and effects of rheumatoid arthritis such as rapid urbanization, new occupation, and lifestyle changes. ${ }^{5}$

Currently, controversy remains about the best therapeutic alternative for this disease when evaluated from a cost-effectiveness viewpoint. It is very essential to assess cost effective treatment option for RA. Two treatment alternatives were compared: complementary and alternative medicine (CAM) and conventional

1. Chairman, Public Health Informatics Foundation (PHIF), Dhaka, Bangladesh.

2. Anu Aggarwal Foundation,Maharashtra, India.

Correspondence: Jakir Hossain Bhuiyan Masud. e-mail:jakir_msd@yahoo.com 
medicine (CM). In a developing country with low resources for drug acquisition and care for drug-related complications, it is essential to conduct cost-effectiveness assessment.

The measuring of health and health-related quality of life is a fast growing field. Utility of the different type of healthcare is not same. Patient takes CAM, CM according to their satisfaction but their efficacy may not be the same. Cost and outcome of both the medicines may also differ. EuroQol 5D (EQ-5D) is an instrument, developed within the framework of a joint European project, which makes it possible to measure quality of life. Preferences can be measured using questionnaires, such as the EQ-5D. ${ }^{6}$ The economic burden of RA is high for healthcare costs and loss of productivity. 7,8 A study showed that the EQ-5D was more responsive than the SF-6D for RA. ${ }^{9}$

Bangladesh is a developing country bravely fighting poverty, illiteracy, ill health and other accompanying ailments. The severity of RA can range from self-limiting disease to severe destruction. ${ }^{10,11}$ Increasing the burden of RA, financing gap at both household level and government level are likely to emerge in Bangladesh. Since RA requires specialized care and huge expenditure in pertaining to it, the aim of this study was to identify the cost-effective treatment of RA.

\section{Materials and method}

This was a cross sectional study. The data were collected among rheumatoid arthritis patients treated in Dhaka Medical College Hospital $(\mathrm{DMCH})$ and Government Unani and Ayurvedic Medical College Hospital (GUAMCH) of Bangladesh by primary sources in the study. The study period was 6 months from August 2008 to February 2009. Respondents were interviewed by using a semi-structured questionnaire. We included the RA patients who were treated by CAM or CM for six months. In our study, ayurvedic medicine is used as CAM and allopathic medicine as CM. The economic analysis included medication costs. Measurement of outcome is used in the economic analysis data on health-related quality of life (using the EQ-5D instrument). The sample size of the study was $60(\mathrm{CM}=30, \mathrm{CAM}=30)$ Data were analyzed by Statistical Package for the Social Sciences (SPSS) software (Version 16).

Considering the scenario of a patient with severe joint pain secondary to knee and/or hip RA, a comparison of the costs generated by medical care of patients with RA receiving any of the two possible treatment alternatives was proposed. These alternatives were based on allopath (Tablet Leflunomide $10 \mathrm{mg} / 100 \mathrm{mg}$ twice daily; Tablet Diclofenac $100 \mathrm{mg}$ twice daily, and Tablet Methotraxate $2.5 \mathrm{mg} 3$ pieces weekly), and CAM (Tablet Nagendra $500 \mathrm{mg}$ twice daily, and Syrup Rashnashab $15 \mathrm{ml}$ twice daily). The treatment was provided for at least 6 months.

This study was approved by Institute of Health Economics, University of Dhaka.

\section{Results}

Our study describes the results of both treatment options. Table I shows, among the total 60 patients, mean $( \pm \mathrm{SD})$ age was $28.88( \pm 6.15)$ years. For CM, male was $43.33 \%$ and female was $56.66 \%$ and, for CAM, male was $46.66 \%$ and female was $53.33 \%$. Female suffered more often than the male $(\mathrm{p}<0.001)$.

Table I: Distribution of the socio-demographic characteristics of respondents

\begin{tabular}{lllll}
\hline $\begin{array}{l}\text { Socio-demographic } \\
\text { characteristics }\end{array}$ & Frequency & Percentage (\%) & Frequency & Percentage (\%) \\
\hline Gender & & & & \\
Male & 14 & 46.66 & 13 & 43.33 \\
Female & 16 & 53.33 & 17 & 56.66 \\
Age of respondent (years) & & & \\
$19-23$ & 8 & 26.66 & 10 & 33.33 \\
$24-28$ & 12 & 40 & 13 & 43.33 \\
$29-33$ & 10 & 33.33 & 7 & 23.33 \\
Mean age ( \pm SD) & & $28.88( \pm 6.15)$ & & \\
Employment status & & & & \\
Employed & 18 & 60 & 16 & 53.33 \\
Unemployed & 12 & 40 & 14 & 46.66 \\
Educational status & & & & \\
Illiterate & 3 & 10 & 2 & 6.66 \\
Primary & 7 & 23.33 & 5 & 16.66 \\
Secondary & 8 & 26.66 & 12 & 40 \\
University & 12 & 40 & 11 & 36.66 \\
\hline
\end{tabular}

In Table II parameters of health-related quality of life (using the EQ-5D6 instrument) are shown where complementary and alternative medicine (CAM) seems to give better response than conventional medicine (CM). 
Table II: Comparison of EQ-5D features between CAM and CM

\begin{tabular}{lcc}
\hline EQ-5D features & $\begin{array}{c}\text { CAM (n=30) } \\
\text { Frequency (\%) }\end{array}$ & $\begin{array}{c}\text { CM (n=30) } \\
\text { Frequency (\%) }\end{array}$ \\
\hline Mobility & $12(40)$ & $20(66.66)$ \\
No mobility & $18(60)$ & $10(33.33)$ \\
Mobility & & $17(56.66)$ \\
Self-care & $9(30)$ & $13(43.33)$ \\
Not Able & $21(70)$ & \\
Able & & $9(30)$ \\
Usual activity & $19(63.33)$ & $21(70)$ \\
No problem & $11(36.66)$ & $8(26.66)$ \\
Problem & & $22(73.33)$ \\
Pain & $21(70)$ & $11(36.66)$ \\
No pain & $9(30)$ & $19(63.33)$ \\
Painful & & \\
Anxiety & $18(60)$ & \\
No Anxious & $12(40)$ & \\
Anxious &
\end{tabular}

It is observed that the cost of conventional medicine is higher than the complementary medicine using EQ-5D. (Table III)

Table III: Comparison of both medicine's average cost in Bangladeshi Taka (BDT)

\begin{tabular}{lc}
\hline Treatment option & Average cost (monthly) \\
\hline CM & 2650 \\
CAM & 1400
\end{tabular}

Table IV: Comparison of both medicine's EuroQol5D (Outcome)

\begin{tabular}{lcc}
\hline Treatment option & $\begin{array}{c}\text { EuroQol5D (EQ-5D) Score } \\
\text { (Average) }\end{array}$ & Outcome (Average) \\
\hline $\mathrm{CM}$ & 3.03 & 0.202 \\
$\mathrm{CAM}$ & 3.59 & 0.239 \\
\hline
\end{tabular}

We find the outcome is better in CAM than CM by EuroQo15D (higher EuroQol shows higher outcme or effectiveness).

\section{Discussion}

Treatment demonstrating the best costeffectiveness result was CAM. In the analysis, both in the construction of the acceptability and in the estimation of economic benefits, the most cost-effective option was CAM.

A study of Mahadeva et al. found that quality of health was measured well for the treatment of dyspepsia using EQ-5D. ${ }^{12}$ Our study also shows the same finding for RA. A study of Tamhane et al. noted that CAM is effective than $\mathrm{CM}$ for the treatment of RA. ${ }^{13}$ Through this costeffectiveness analysis, it has been shown that CAM was superior to CM. There was a lower use of resources with this type of treatment, especially due to a lower rate of adverse events, resulting in a decrease in health care costs. Thus, currently it may be considered that this may be an alternative treatment option for RA.

This investigation conducted an economic evaluation considering both health status and the cost for medical care associated with the use of CAM and CM. In this study, we were more specific with the effectiveness measure, making the differences among drugs more evident. In our study, health care costs of CAM is $1410 \mathrm{BDT}$ and $\mathrm{CM}$ is $2650 \mathrm{BDT}$. On the otherhand outcome (EQ 5D) of CAM is 0.239 (average) and CM is 0.202 (average).When integrating both measures (costs and effectiveness) within the deterministic analysis, it is observed that CAM is superior to $\mathrm{CM}$, with a lower cost and higher effectiveness. The results of this study are similar to other models published where the use of the CAM is the most cost-effective.

\section{Conclusion}

For the least expensive drug and more effective treatment of RA, we can consider the CAM. With this analysis, it may be stated that the use of CAM, is cost-effective, which may reduce cost and improve health condition of RA patient. However, there is a need for future cost-effectiveness study in a larger scale, especially with respect to controlling the cost for society, consider pre-treatment and post-treatment option and medical investigation.

\section{References}

1. Barbour KE, Helmick CG, Boring M, Brady TJ. Vital Signs: Prevalence of Doctor-Diagnosed Arthritis and Arthritis-Attributable Activity Limitation-United States, 2013-2015. MMWR. Morbidity and Mortality Weekly Report. 2017;66(9):246-53. 
2. Muirden KD. The Developing Relationship between the World Health Organization and the International League against Rheumatism. The Journal of Rheumatology. 1991;18(6):793.

3. Gabriel SE, Michaud K. Epidemiological Studies in Incidence, Prevalence, Mortality, and Comorbidity of the Rheumatic Diseases. Arthritis Research \& Therapy. 2009;11(3):229.

4. El-Gabalawy H, Guenther LC, Bernstein CN. Epidemiology of Immune-Mediated Inflammatory Diseases: Incidence, Prevalence, Natural History, and Comorbidities. The Journal of Rheumatology Supplement. 2010;85:2-10.

5. Muirden KD. Epidemiology and Community Studies: Asia/Pacific Region. Bailliere's Clinical Rheumatology. 1995;9(1):11-20.

6. Brooks R \& Group E. EuroQol: The Current State of Play. Health Policy. 1996;37(1):53-72.

7. Boonen A, Severens JL. The Burden of Illness of Rheumatoid Arthritis. Clinical Rheumatology. 2011;30(1):3-8.
8. Zhang W, Anis AH The Economic Burden of Rheumatoid Arthritis: Beyond Health Care Costs. Clinical Rheumatology. 2011;30(1):25-32.

9. Conner-Spady B, Suarez-Almazor ME Variation in the Estimation of Quality-Adjusted Life-Years by Different Preference-Based Instruments. Medical Care.2003;41(7):791-801.

10. Klippel JH, Stone JH, Crofford LJ, White P, editors. Primer on the Rheumatic Diseases. 12th ed. Arthritis Foundation Atlanta; Springer. 2001.

11. Scott DL, Steer S. The Course of Established Rheumatoid Arthritis. Best Practice \& Research Clinical Rheumatology. 2007;21(5):943-67.

12. Mahadeva S, Wee HL, Goh KL, Thumboo J. The EQ-5D (Euroqol) is a Valid Generic Instrument for Measuring Quality of Life in Patients with Dyspepsia. BMC Gastroenterology. 2009;9(1):20.

13. Tamhane A, McGwin Jr. G, Redden DT, Hughes LB, Brown EE, Westfall AO, et al. Complementary and Alternative Medicine Use in African Americans with Rheumatoid Arthritis. Arthritis Care \& Research. 2014;66(2):180-89. 